\title{
The Application Prospect Autologous Bone Marrow Extract Buffy Coat in Cartilage Tissue Engineering: A Mini-Review
}

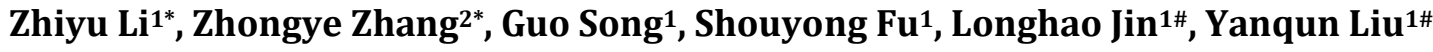 \\ ${ }^{1}$ Department of Orthopedic Surgery, Yanbian University Hospital, Yanji, China \\ ${ }^{2}$ Department of Orthopedic Surgery, Songyuan Central Hospital, Songyuan, China \\ Email: "jlh0423@sina.com
}

How to cite this paper: Li, Z.Y., Zhang, Z.Y., Song, G., Fu, S.Y., Jin, L.H. and Liu, Y.Q. (2019) The Application Prospect Autologous Bone Marrow Extract Buffy Coat in Cartilage Tissue Engineering: A Mini-Review. Journal of Biosciences and Medicines, 7, 9-17.

https://doi.org/10.4236/jbm.2019.712002

Received: October 23, 2019

Accepted: November 28, 2019

Published: December 2, 2019

Copyright $\odot 2019$ by author(s) and Scientific Research Publishing Inc. This work is licensed under the Creative Commons Attribution International License (CC BY 4.0).

http://creativecommons.org/licenses/by/4.0/

\begin{abstract}
Cartilage injury is an important cause of osteoarthritis; however, there is no effective method of cartilage regeneration at present. Therefore, it would be of great value to explore and develop new methods of cartilage regeneration. In recent years, it has become a hot topic on repairing damaged cartilage by using tissue engineered cartilage domestic and abroad. It's the key factor to success for getting cell source which is effective, applicable and easy to obtain in the technology of cartilage tissue engineering filed. This article summarizes the research progress of bone marrow extract buffy coat in cartilage tissue engineering.
\end{abstract}

\section{Keywords}

Buffy Coat, Cartilage, Tissue Engineering

\section{Introduction}

Osteoarthritis (OA), with a high incidence and morbidity rate and a long treatment process, results in huge economic burden to society and people and effects on physical and mental health of patients. The cartilage injury is an important cause of knee osteoarthritis. At present, the commonly used methods for the treatment including arthroscopic debridement, subchongdral bone drilling, microfracture, auto or allo osteochondral transplantation, and autologous chondrocyte transplantation [1] [2]. Nevertheless, there is no effective method for articular cartilage regeneration. Therefore, it has great value to explore and devel- 
op new methods for cartilage regeneration.

Recently, repairing the injured cartilage with tissue engineered cartilage has become a hot topic domestic and abroad. The main components of tissue engineered cartilage are seed cells, scaffold materials and growth factors. Among the seed cells, chondrocyte, mesenchymal stem cell (MSC) and induced human pluripotent stem cell (iPS) are the most commonly used. MSC is an important source of tissue engineering seed because of the convenience for acquiring, simple isolation and cultivation, and its strong reproductive capacity [3]. However, the differentiative capacity of MSC shows a gradual decrease during culture passage in vitro, on the other hand, various cytokines for differentiation of MSC are needed. The differentiation factors of MSC include transforming growth factor- $\beta$ (TGF- $\beta$ ), insulin-like growth factor (IGF), bone morphogenic proteins (BMP), fibroblast growth factor (FGF), et al. [4]. However, the mechanisms and regulatory effects of these cytokines are still not completely understood, which limits their clinical application.

Therefore, it becomes a research focus that how to overcome the complicated process, the cost of cell culture in vitro, the risk of using various growth factors, and the use of autologous growth factors without culture in vitro. Furthermore, it is also a shortcut for tissue engineering technology to be applied in clinical practice.

\section{Cartilage Tissue Engineering}

Scaffold: In order to copy the target tissue of ECM characteristics, cells are usually seeded onto a scaffold in tissue engineering. By imitating ECM, biomaterials provide an environmental structure that supports cell activity, proliferation, and secretion [5]. These biomaterials include synthetic and natural matrices, which could be distinguished by proteins or polysaccharides [6]. The ideal biomaterial should be biocompatible to prevent inflammation and immune response. It must be permeable to allow the diffusion of molecules, nutrients, and growth factors. Finally, it should be biodegradable so that it is enough to be integrated into the physiological process of tissue remodeling. Ideally, it should be injectable to allow implantation through minimally invasive surgery. The representatives of synthetic materials include polyglycolic acid (PGA), polylactic acid (PLA) and polydioxanone [7]. The representatives of natural materials are membranes of type I and III collagen, type I collagen gel and hyaluronic acid matrix [8] [9]. There are still many new materials besides the ones have been presented as above.

Growth factors: Growth factors could stimulate cell proliferation and differentiation, and prevent apoptosis and secretion of extracellular matrix. In cartilage tissue engineering, GF- $\beta 1$, as most commonly used growth factor, is associated with regulation of proliferation, differentiation and ECM synthesis [10]. IGF-1 induces a plethora of anabolic effects and decreases catabolic responses. With collagen type II matrix, cartilage defects filled with IGF-1 can be repaired more efficiently [11]. FGF-2 treatment of bone marrow-derived MSC monolayer cul- 
tures results in enhancing proteoglycan synthesis and cell proliferation [12]. Platelet-derived growth factors (PDGF) was the first growth factor reported and its role and function were primarily linked with every type of injury healing based [13]. BMPs have been shown to regulate chondrocyte proliferation independently. However, in parallel to Indian hedgehog (IHH) [14], with BMP2 and BMP4 are especially important for chondrocyte proliferation and differentiation [15].

Cell: Chondrocytes, fibroblasts, stem cells and iPS cells have all been tested in cartilage engineering. However, chondrocytes and MSCs remain the most largely investigated sources of chondrogenic cells for cartilage repair [3].

\section{MSC-Based Cartilage Repair}

The differentiation abilities of MSC to cartilage in vitro have long been demonstrated. The study of cartilage differentiation of MSC was mainly focused on inducing chondrocyte differentiation in vitro by using TGF- $\beta$, IGF, BMP, FGF and various kinds of cytoskeleton. However, the regulation mechanism of these factors is still unclear, which limits the clinical practice. In order to avoid the above restrictions, many researchers injected proliferating MSC into injured cartilage without differentiation in vitro. However, the MSC without induction appears a long transform period into chondrocyte with low efficiency, resulting in fibrocartilage with chondrocyte hypertrophy [16]. Therefore, the research on the treatment of cartilage injury and osteoarthritis with MSC has been changed to search cytokines and growth factors available for clinic practice. It has been reported that the chondrocyte regeneration abilities of chondrogenic progenitor cells and autologous PRP mixture have exceeded that of MSC [17]. According to these results, we speculate that autologous PRP is a potential source of growth factors and cytokines. However, due to the limited source and cumbersome sampling of chondrogenic progenitor cells, the shortcomings of cell proliferation in vitro have not been overcome yet.

\section{The Effect of Platelet-Rich Plasma (PRP) on Cartilage}

Platelet-rich plasma (PRP) is a self-concentrated mixed cytokine produced by centrifuging peripheral blood. PRP contains a lot of growth factors and cytokines, such as platelet growth factor (PDGF), epidermal growth factor (EGF), IGF-1, TGF- $\beta 1$, vascular endothelial growth factor (VEGF), hepatocyte growth factor (HGF) and FGF, as well as other unknown growth factors [18] [19]. These components of PRP determine their multiple roles. For example, enhance anabolism, anti-inflammatory, and cell differentiation.

Studies showed that PRP played a critical role in articular cartilage repair and regeneration by stimulating the migration, proliferation and differentiation of MSC, which results in alleviating the symptoms of osteoarthritis and delaying cartilage degeneration. Except for relief of symptoms, PRP also could inhibit inflammatory response by nuclear factor kappa-B (NF-kB) signaling pathway, 
leading to relieve pain. Furthermore, PRP not only can promote tissue regeneration, also lubricate cartilage by reducing friction and wear [20]. Despite all these advantages, the therapeutic effect of PRP is still limited because of not carrying MSC and heterogeneous [21]. Therefore, it can only be used as cytoskeleton, growth factors or cytokines.

\section{Cartilage Regeneration from Bone Marrow Concentrate (BMC)}

Bone marrow concentrate (BMC) is the product extracted from interface between erythrocyte and plasma after centrifugation of bone marrow. Its components include some surface erythrocyte, white blood cells on the surface of erythrocyte and some bottom plasma. BMC can be applied immediately to patients without any treatment, and many regulatory agencies have approved it for clinical use. Except for MSC, BMC also contains many biologically active molecules and cells, including lymphocytes, neutrophils, monocytes and platelets. Therefore, some researchers consider that BMC is the product of PRP plus MSC. In fact, there are many different cytokines and growth factors between BMC and PRP. There are few cytological analyses of BMC in orthopaedics. A study showed that BMC contained a lot of platelets, monocytes and CD34 positive cells [22]. Cassano also demonstrated BMC is rich in interleukin-1 receptor antagonist (IL-1ra) [22]. As a natural receptor antagonist of natural IL-1, IL-1ra can be used in treating autoimmune diseases, such as rheumatoid arthritis, which is an interesting finding for clinicians. Furthermore, BMC also contains interleukin-1 beta (IL-1 beta) and interleukin-8 (IL-8) which are not found in PRP. However, there is a lot of red blood cell (RBC) in BMC. Horn et al. reported that RBC could restrain the adhesion and proliferation of MSC [23]. In a word, the key point of using BMC in cartilage injury treatment is to overcome the effect on adhesion and proliferation of RBC. We thought maybe the buffy coat is the BMC removing RBC.

\section{Buffy Coat}

Buffy coat is a mixture of white blood cells, platelets and serum after blood or bone marrow centrifugation. When the blood or bone marrow was centrifuged, we could acquire three different distinct layers. After centrifugation, one is transparent liquid (plasma), the other one is red liquid containing most red blood cells, and in the middle, a thin layer of liquid (Buffy coat) can be distinguished (Figure 1).

Buffy coat (we call it "Buffy coat", because its color is usually light yellow) accounts for less than $1 \%$ of the total sample, which contains most white blood cells and platelets. In practice, the deoxyribonucleic acid (DNA) of buffy coat is usually derived from mammalian blood, because mammalian red blood cells are nuclear-free and do not contain DNA.

Under experimental conditions, the MSC in blood or bone marrow is often 
derived from buffy coat. There are large number of monocytes (MNCs) $(2.3 \times$ $10^{6} / \mathrm{ml}$, bone marrow) in buffy coat, which contains MSC [24]. Ficoll density gradient is often used to obtain buffy coat in the laboratory. First, the samples were diluted with PBS (1:3), and pipetting to prevent the samples from coagulating (to ensure that there were no blood clots in the samples). Next, Ficoll with a total sample size of $1 / 3$ should be placed in the centrifugal tube, and then the sample should be slowly placed in the centrifugal tube (never mixed with Ficoll). For specific gravity, the sample will be above Ficoll. Then be centrifuged under $1000 \mathrm{~g}$ centrifugal force for 30 minutes [25]. After centrifuged, we could see a red liquid (erythrocyte layer) at the bottom of the centrifugal tube, with a transparent and colorless Ficoll layer, and a mixture of serum and PBS on the top. There is a translucent layer between Ficoll and serum PBS mixture, which is called buffy coat (Figure 2).

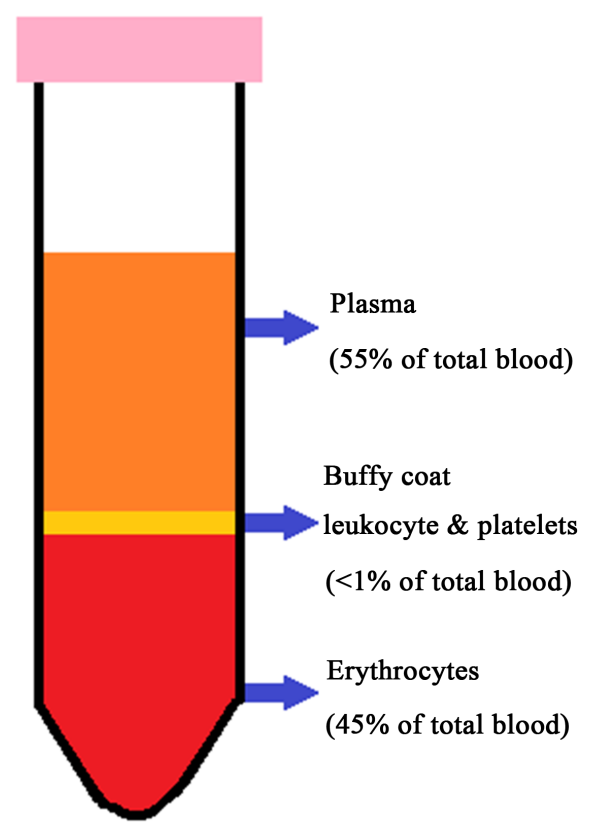

Figure 1. Traditional buffy coat.

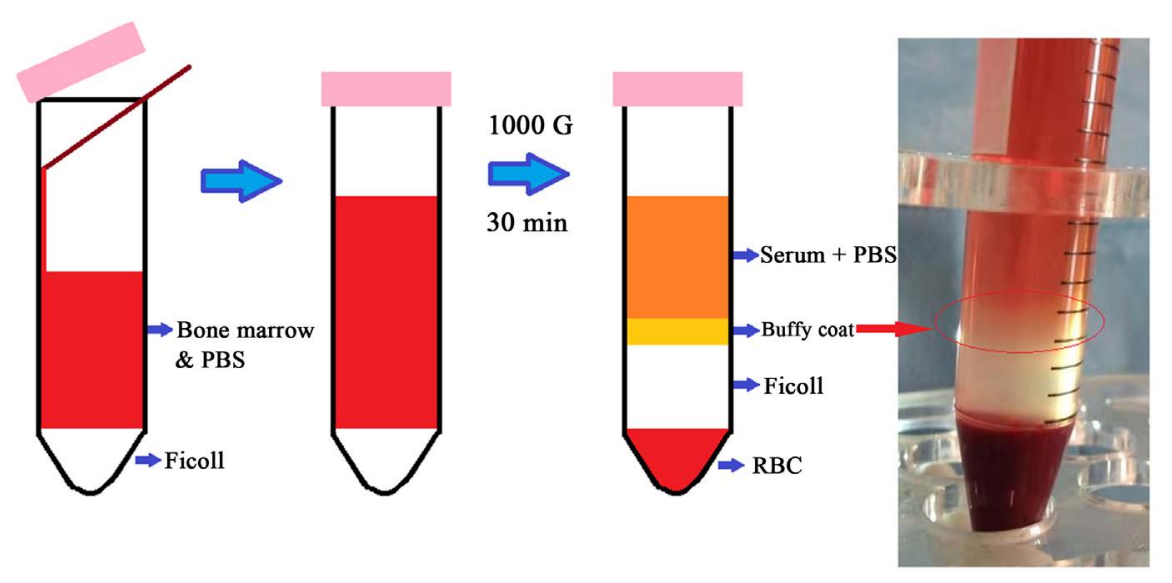

Figure 2. Ficoll gradient centrifugation. 


\section{Cartilage Regeneration from Bone Marrow Derived Buffy Coat}

In vivo study, Jin et al. (2011) firstly observed that the buffy coat contained monocytes, lymphocytes, macrophages, platelets, and various cytokines displayed good cartilage regeneration [24]. As the achieved number of MSCs in the buffy coat are higher than that of the bone marrow stimulation (100 times). The buffy coat of $4 \mathrm{ml}$ bone marrow contained 2400 MSCs.

In vitro study, the positive control group was cultured in the cartilage culture medium supplemented with TGF- $\beta 3(10 \mathrm{ng} / \mathrm{ml})$ after adding $5 \times 10^{6} \mathrm{MSC}$ to each sample; the Buffy coat group, each sample was supplemented with $2 \mathrm{ml}$ buffy coat which from the bone marrow, and then cultured in the chondrogenic medium without TGF- $\beta 3$. Three weeks later, tissue engineered cartilage was observed in both groups. However, necrosis could be seen in the middle of the cartilage in positive control group, but in buffy coat group, it was differentiated into cartilage in all aspects [26].

It has been proved that buffy coat plays an important role in chondrogenesis in vivo and in vitro study. Buffy coat is rich in MSC, cytokines and growth factors, and also successfully overcomes RBC incorporation. Buffy coat is more likely to generate tissue engineered cartilage, because of no RBC, which prevents MSC adhesion and proliferation. The greatest advantages of buffy coat are that it has no autogenous rejection, no need to be cultured in vitro, and without growth factors.

\section{Application Prospect of Buffy Coat}

The effect of buffy coat on cartilage regeneration has been verified [24] [26], and not only in cartilage regeneration, but also in many areas of tissue regeneration, such as bone defect, nonunion, cardiac tissue regeneration, nerve injury, skin defect, etc. It will become a new source in the field of tissue engineering.

\section{The Shortcomings of Buffy Coat}

Buffy coat is difficult to be fixed in the damaged tissue because it is liquid. It contains various factors and cells, however, it is lack of one of the three elements of tissue engineering cytoskeleton. Therefore, leading to the research hotspots has shifted to seek for scaffold which matching the properties of buffy coat and different scaffolds for different tissues.

\section{Conclusion}

Although there are still many problems in the application of buffy coat, with the continuous development of materials and technology, such as three-dimensional printing technology, electrospinning technology, we believe that buffy coat will overcome the clinical scientific problems of cartilage injury by multi-disciplinary and multi-field cooperation and comprehensive utilization of materials science, biomechanics, physiology and other related expertise. 


\section{Acknowledgements}

This study was supported by the grant of the National Natural Science Foundation of China (81560353); China Postdoctoral Science Foundation (2016M601394); Jilin Postdoctoral Science Foundation, China; The Science and Technology Research Project of the Department of Education, Jilin, China.

\section{Conflicts of Interest}

The authors declare no conflicts of interest regarding the publication of this paper.

\section{References}

[1] Dozin, B., Malpeli, M., Cancedda, R., Bruzzi, P., Calcagno, S., Molfetta, L., Priano, F., Kon, E. and Marcacci, M. (2005) Comparative Evaluation of Autologous Chondrocyte Implantation and Mosaicplasty: A Multicentered Randomized Clinical Trial. Clinical Journal of Sport Medicine, 15, 220-226. https://doi.org/10.1097/01.jsm.0000171882.66432.80

[2] Komárek, J., Vališ, P., Repko, M., Chaloupka, R. and Krbec, M. (2010) Treatment of Deep Cartilage Defects of the Knee with Autologous Chondrocyte Transplantation: Long-Term Results. Acta Chirurgiae Orthopaedicae et Traumatologiae Cechoslovaca, 77, 291-295.

[3] Hubka, K.M., Dahlin, R.L., Meretoja, V.V., Kasper, F.K. and Mikos, A.G. (2014) Enhancing Chondrogenic Phenotype for Cartilage Tissue Engineering: Monoculture and Coculture of Articular Chondrocytes and Mesenchymal Stem Cells. Tissue Engineering Part B: Reviews, 20, 641-654. https://doi.org/10.1089/ten.teb.2014.0034

[4] Yu, D.A., Han, J. and Kim, B.S. (2012) Stimulation of Chondrogenic Differentiation of Mesenchymal Stem Cells. International Journal of Stem Cells, 5, 16-22. https://doi.org/10.15283/ijsc.2012.5.1.16

[5] Vinatier, C. and Guicheux, J. (2016) Cartilage Tissue Engineering: From Biomaterials and Stem Cells to Osteoarthritis Treatments. Annals of Physical and Rehabilitation Medicine, 59, 139-144. https://doi.org/10.1016/j.rehab.2016.03.002

[6] Vinatier, C., Bouffi, C., Merceron, C., Gordeladze, J., Brondello, J.M., Jorgensen, C., Weiss, P., Guicheux, J. and Noël, D. (2009) Cartilage Tissue Engineering: Towards a Biomaterial-Assisted Mesenchymal Stem Cell Therapy. Current Stem Cell Research \& Therapy, 4, 318-329. https://doi.org/10.2174/1574888809789649205

[7] Ossendorf, C., Kaps, C., Kreuz, P.C., Burmester, G.R., Sittinger, M. and Erggelet, C. (2007) Treatment of Posttraumatic and Focal Osteoarthritic Cartilage Defects of the Knee with Autologous Polymer-Based Three-Dimensional Chondrocyte Grafts: 2-Year Clinical Results. Arthritis Research \& Therapy, 9, R41. https://doi.org/10.1186/ar2180

[8] Cherubino, P., Grassi, F.A., Bulgheroni, P. and Ronga, M. (2003) Autologous Chondrocyte Implantation Using a Bilayer Collagen Membrane: A Preliminary Report. Journal of Orthopaedic Surgery (Hong Kong), 11, 10-15. https://doi.org/10.1177/230949900301100104

[9] Ochi, M., Uchio, Y., Kawasaki, K., Wakitani, S. and Iwasa, J. (2002) Transplantation of Cartilage like Tissue Made by Tissue Engineering in the Treatment of Cartilage Defects of the Knee. The Journal of Bone and Joint Surgery. British Volume, 84, 571-578. https://doi.org/10.1302/0301-620X.84B4.0840571 
[10] Branly, T., Contentin, R., Desancé, M., Jacquel, T., Bertoni, L., Jacquet, S., Mallein-Gerin, F., Denoix, J.M., Audigié, F., Demoor, M. and Galéra, P. (2018) Improvement of the Chondrocyte-Specific Phenotype upon Equine Bone Marrow Mesenchymal Stem Cell Differentiation: Influence of Culture Time, Transforming Growth Factors and Type I Collagen siRNAs on the Differentiation Index. International Journal of Molecular Sciences, 19, pii: E435. https://doi.org/10.3390/ijms19020435

[11] Bai, Z., Guo, X.H., Tang, C., Yue, S.T., Shi, L. and Qiang, B. (2018) Effects of Artesunate on the Expressions of Insulin-Like Growth Factor-1, Osteopontin and C-Telopeptides of Type II Collagen in a Rat Model of Osteoarthritis. Pharmacology, 101, 1-8. https://doi.org/10.1159/000479160

[12] Maehara, H., Sotome, S., Yoshii, T., Torigoe, I., Kawasaki, Y., Sugata, Y., Yuasa, M., Hirano, M., Mochizuki, N., Kikuchi, M., Shinomiya, K. and Okawa, A. (2010) Repair of Large Osteochondral Defects in Rabbits Using Porous Hydroxyapatite/Collagen (HAp/Col) and Fibroblast Growth Factor-2 (FGF-2). Journal of Orthopaedic Research, 28, 677-686. https://doi.org/10.1002/jor.21032

[13] Schmidt, M.B., Chen, E.H. and Lynch, S.E. (2006) A Review of the Effects of Insulin-Like Growth Factor and Platelet Derived Growth Factor on in Vivo Cartilage Healing and Repair. Osteoarthritis and Cartilage, 14, 403-412. https://doi.org/10.1016/j.joca.2005.10.011

[14] Minina, E., Kreschel, C., Naski, M.C., Ornitz, D.M. and Vortkamp, A. (2002) Interaction of FGF, Ihh/Pthlh, and BMP Signaling Integrates Chondrocyte Proliferation and Hypertrophic Differentiation. Developmental Cell, 3, 439-449. https://doi.org/10.1016/S1534-5807(02)00261-7

[15] Duprez, D., Bell, E.J., Richardson, M.K., Archer, C.W., Wolpert, L., Brickell, P.M. and Francis-West, P.H. (1996) Overexpression of BMP-2 and BMP-4 Alters the Size and Shape of Developing Skeletal Elements in the Chick Limb. Mechanisms of Development, 57, 145-157. https://doi.org/10.1016/0925-4773(96)00540-0

[16] Mazor, M., Lespessailles, E., Coursier, R., Daniellou, R., Best, T.M. and Toumi, H. (2014) Mesenchymal Stem-Cell Potential in Cartilage Repair: An Update. Journal of Cellular and Molecular Medicine, 18, 2340-2350.

https://doi.org/10.1111/jcmm.12378

[17] Wang, K., Li, J., Li, Z., Wang, B., Qin, Y., Zhang, N., Zhang, H., Su, X., Wang, Y. and Zhu, H. (2019) Chondrogenic Progenitor Cells Exhibit Superiority over Mesenchymal Stem Cells and Chondrocytes in Platelet-Rich Plasma Scaffold-Based Cartilage Regeneration. The American Journal of Sports Medicine, 47, 2200-2215. https://doi.org/10.1177/0363546519854219

[18] Pietrzak, W.S. and Eppley, B.L. (2005) Platelet Rich Plasma: Biology and New Technology. Journal of Craniofacial Surgery, 16, 1043-1054. https://doi.org/10.1097/01.scs.0000186454.07097.bf

[19] Gaissmaier, C., Koh, J.L. and Weise, K. (2008) Growth and Differentiation Factors for Cartilage Healing and Repair. Injury, 39, S88-S96.

https://doi.org/10.1016/j.injury.2008.01.035

[20] Zhu, Y., Yuan, M., Meng, H.Y., Wang, A.Y., Guo, Q.Y., Wang, Y. and Peng, J. (2013) Basic Science and Clinical Application of Platelet-Rich Plasma for Cartilage Defects and Osteoarthritis: A Review. Osteoarthritis Cartilage, 21, 1627-1637. https://doi.org/10.1016/j.joca.2013.07.017

[21] Xie, X., Zhang, C. and Tuan, R.S. (2014) Biology of Platelet-Rich Plasma and Its Clinical Application in Cartilage Repair. Arthritis Research \& Therapy, 16, 204. https://doi.org/10.1186/ar4493 
[22] Cassano, J.M., Kennedy, J.G., Ross, K.A., Fraser, E.J., Goodale, M.B. and Fortier, L.A. (2016) Bone Marrow Concentrate and Platelet-Rich Plasma Differ in Cell Distribution and Interleukin 1 Receptor Antagonist Protein Concentration. Knee Surgery, Sports Traumatology, Arthroscopy, 26, 333-342. https://doi.org/10.1007/s00167-016-3981-9

[23] Horn, P., Bork, S. and Wagner, W. (2011) Standardized Isolation of Human Mesenchymal Stromal Cells with Red Blood Cell Lysis. Methods in Molecular Biology, 698, 23-35. https://doi.org/10.1007/978-1-60761-999-4_3

[24] Jin, L.H., Choi, B.H., Kim, Y.J., Park, S.R., Jin, C.Z. and Min, B.H. (2011) Implantation of Bone Marrow-Derived Buffy Coat Can Supplement Bone Marrow Stimulation for Articular Cartilage Repair. Osteoarthritis Cartilage, 19, 1440-1448.

https://doi.org/10.1016/j.joca.2011.07.012

[25] Yoon, S.H., Shim, Y.S., Park, Y.H., Chung, J.K., Nam, J.H., Kim, M.O., et al. (2007) Complete Spinal Cord Injury Treatment Using Autologous Bone Marrow Cell Transplantation and Bone Marrow Stimulation with Granulocyte Macrophage-Colony Stimulating Factor: Phase I/II Clinical Trial. Stem Cells, 25, 2066-2073. https://doi.org/10.1634/stemcells.2006-0807

[26] Jin, L.H., Zhang, Z.Y., Liu, Y.Q., Gurung, K., Jin, Y.J., He, Y.M., Jin, Y. and Jin, Z.H. (2018) Comparison of Chondrogenic Ability between Mesenchymal Stem Cells and Buffy Coat in Vitro. Journal of Biosciences and Medicines, 6, 86-94.

https://doi.org/10.4236/jbm.2018.63006 